\title{
Study on support optimization of coal roadway with soft and broken surrounding rock
}

\author{
$\operatorname{Li~} \mathrm{Li}^{1,2, *}$ \\ ${ }^{1}$ School of Mechanics and Civil Engineering, China University of Mining and Technology (Beijing), 100083 Beijing, China \\ ${ }^{2}$ Shuangliu coal mine, Shanxi Fenxi Mining (Group) Co., Ltd, 033300 Shanxi, China
}

\begin{abstract}
With the increase of mining depth, the geological conditions tend to be complex. The problems of high mine pressure and soft and broken surrounding rock are more serious, and the difficulty of support is significantly increased. In this paper, the coal roadway with soft and broken surrounding rock in Shuangliu coal mine was taken as the research object, the model was established by FLAC3D software, the deformation and failure characteristics of the surrounding rock of the roadway were studied, the distribution of the stress and plastic area of the roadway were analyzed, and the problems of the original support scheme were analyzed. Combined with the field investigation and analysis, a variety of optimization schemes were proposed, and the optimal support scheme was obtained through modelling and calculation. The results show that the sidewall and corner of coal roadway are the key parts of support, and strengthening its support strength is conducive to improving the overall stability of the roadway. W-type steel band can be used to connect the rock bolt and anchor cable together to play the role of coupling support, so as to achieve the overall support effect.
\end{abstract}

\section{Introduction}

The stability of coal roadway is of great significance to the safety production of coal mine, but with the increase of mining depth, the surrounding rock of coal roadway is more soft and broken, and the instability of coal roadway often occurs [1-4]. Bolt support can support the surrounding rock in time after coal roadway excavation, and actively play the self bearing capacity of the surrounding rock, thus becoming the main support form of the roadway [5-6]. But reasonable bolt support parameters are the key to ensure the effect of roadway support. At present, the surrounding rock of the coal roadway in Shuangliu coal mine is broken, the mine pressure is large, and the support is very difficult.

In this paper, FLAC3D software was used to build a three-dimensional model of coal roadway in 33407 working face in Shuangliu coal mine to simulate the effect of roadway excavation and support. Through the support comparison of various schemes, the support parameters were optimized to get a reasonable support scheme. On the premise of ensuring the stability of the roadway, the driving speed is increased and the support cost is reduced. Some support laws were summarized, which can provide reference for support design of coal roadway in the future.

\section{Engineering situations}

\subsection{General geology}

The elevation of the 33407 working face in Shuangliu coal mine is $440-485 \mathrm{~m}$. The $(3+4) \#$ coal seam is mined with a thickness of $3.2 \mathrm{~m}$ and a dip angle of $6^{\circ}$. The coal seam is black, soft and broken, with unit weight of 1390 $\mathrm{kg} / \mathrm{m} 3$, calorific value of $23.856 \mathrm{MJ} / \mathrm{kg}$, sulfur content of $0.39 \%$, and cementation index of $70 \%$. The surrounding rock condition of the roadway is shown in Table 1 . The top and direct bottom are sandy mudstones with uneven sand content, a small amount of plant fossils, developed fissures, compressive strength of $33.2 \mathrm{Mpa}$, relatively broken. The section of the roadway is rectangular, with width of $4.6 \mathrm{~m}$, height of $3.2 \mathrm{~m}$ and sectional area of $14.72 \mathrm{~m}^{2}$.

Table 1. Coal roadway surrounding rock distribution.

\begin{tabular}{|c|c|c|}
\hline Name & Rock type & Thickness \\
\hline Roof & $\begin{array}{c}\text { Sandy } \\
\text { mudstone }\end{array}$ & $15.5 \mathrm{~m}$ \\
\hline $\begin{array}{c}\text { Immediate } \\
\text { floor }\end{array}$ & $\begin{array}{c}\text { Sandy } \\
\text { mudstone }\end{array}$ & $5.65 \mathrm{~m}$ \\
\hline Main floor & $\begin{array}{c}\text { Fine } \\
\text { sandstone }\end{array}$ & $12.0 \mathrm{~m}$ \\
\hline
\end{tabular}

\subsection{Original support scheme}

The original support scheme of the roadway is shown in Figure 1 and Figure 2. The roof is supported by rock bolt

\footnotetext{
* Corresponding author: LLSLKD@163.com
} 
+ anchor cable + W-type steel band + net support, the roof bolt is $\Phi 20 \times 2400 \mathrm{~mm}$ threaded steel bolt, and the anchoring method is resin lengthening anchoring. Each bolt is provided with one Z2355 and K2355 type anchoring agent. Five bolts are arranged in each row, and the spacing and row spacing of top bolts are $1000 \mathrm{x}$ $1100 \mathrm{~mm}$. $\Phi 17.8 \times 6400 \mathrm{~mm}$ steel strand is used as the anchor cable, and K2355 and Z2355 type anchoring agents are used for each anchor cable, $900 \mathrm{~mm}$ away from the roadway center line. The specification of $\mathrm{W}$ type steel band is BHW-3-280-4200-5. Metal mesh is laid on the roof.

The sidewall is supported by rock bolt and net, the sidewall bolt is $\Phi 20 \times 2000 \mathrm{~mm}$ screw steel bolt, anchored by resin end, and each bolt is equipped with a K2355 type anchoring agent. The spacing and row spacing of anchor bolts are $1000 \times 1100 \mathrm{~mm}$. The rock bolts are perpendicular to the sidewall. The top row of anchor bolts is $500 \mathrm{~mm}$ from the roof. The sidewall is laid with metal net.

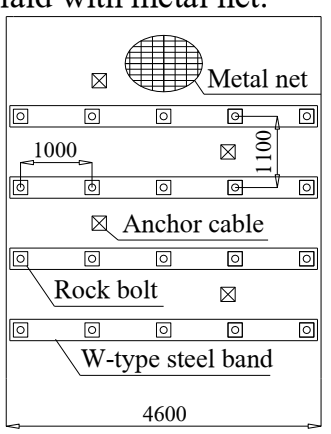

Fig. 1. Roof support.

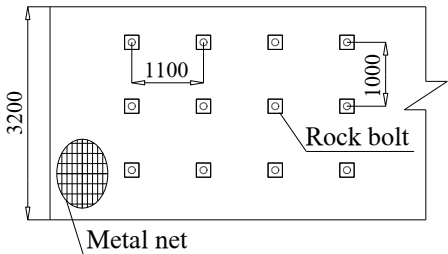

Fig. 2. Sidewall support.

\section{Support effect of the original scheme}

\subsection{Underground investigation and analysis}

Through field investigation, it is found that after the coal roadway is excavated, the original scheme is adopted for support, the surrounding rock of the roadway is loose and weak, the deformation of the sidewall is very large, and some areas are damaged by cross fall, the failure of the side bolt, etc.; the deformation of the corner of the roadway is obvious, and the overall stability of the roadway is poor, so it can be seen that the sidewall and corner are the weak points of the roadway. Preliminary analysis shows that the length and anchorage length of the side bolt are insufficient, and the integrity of the support is poor, which leads to the low strength of the side bolt support and the large deformation of the surrounding rock of the roadway. It can be seen that there is a large optimization space in the original support scheme.

\subsection{Establish numerical model}

By using FLAC3D, a three-dimensional model of the roadway is established to evaluate the supporting effect of the original scheme and find the existing problems. The $3 \mathrm{D}$ model is shown in Figure 3. The size of the numerical model is $30 \times 25 \times 11 \mathrm{~m}$, and the grid is divided according to the lithology layer by layer, and the uneven division method is adopted. The grid division density of the roadway part is larger, and the calculation accuracy is improved [7-8]. The coordinate origin is taken at the center of the roadway bottom, $Z$ axis is vertical upward, $\mathrm{X}$ axis is horizontal right, $\mathrm{Y}$ axis points to the depth. The top of the model adopts the stress boundary condition, the upper surface applies the vertical compressive stress, the side and the bottom adopt the displacement boundary condition, the side applies the normal displacement constraint, and the bottom is fixed displacement [9]. The model adopts Mohr Coulomb constitutive relation, the excavated rock mass is simulated by null model, and the structural elements embedded in the program are used to simulate various supporting components.

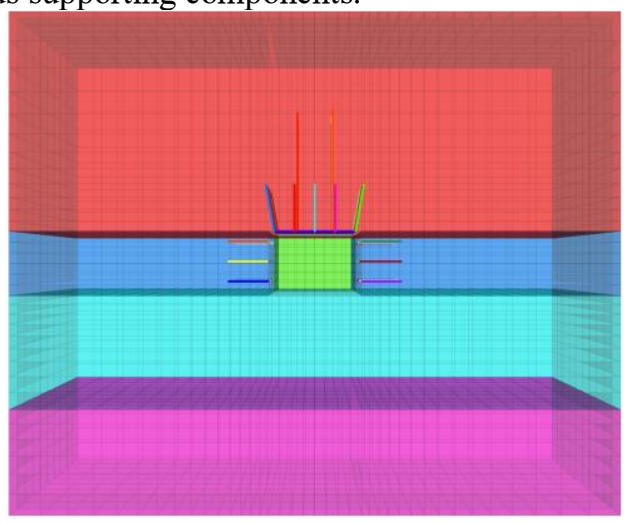

Fig. 3. Numerical model.

\subsection{Simulation results and analysis of the original scheme}

The displacement field is shown in Figure 4. The arrow in the Figure 4 is the displacement vector diagram of the roadway. It can be seen that the displacement of the sidewall is the largest, followed by the roof and then the floor. The maximum displacement point of the sidewall is in the middle position, extending to the depth in a circular arc shape, and the affected area is large. There is a large displacement in the depth of both sides. It can be seen that the size and scope of the deformation of the sidewall have not been effectively controlled. The original scheme of the support of the sidewall is the focus of the improvement.

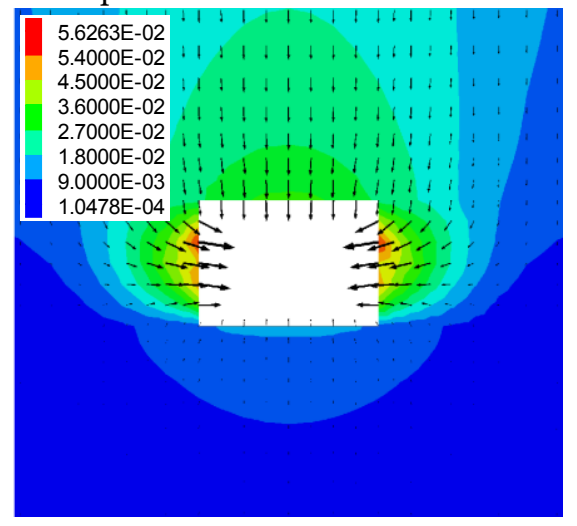

Fig. 4. Nephogram of displacement. 
The maximum principal stress field is shown in Figure 5. It can be seen from the Figure 5 that the stress of the roadway after excavation is released and the stress after support is redistributed. The roof, floor and sidewall of the roadway are obviously affected. The stress concentration appears in the corner of the roadway. The stress state of the surrounding rock of the roadway should be further improved through the optimization of the support parameters.

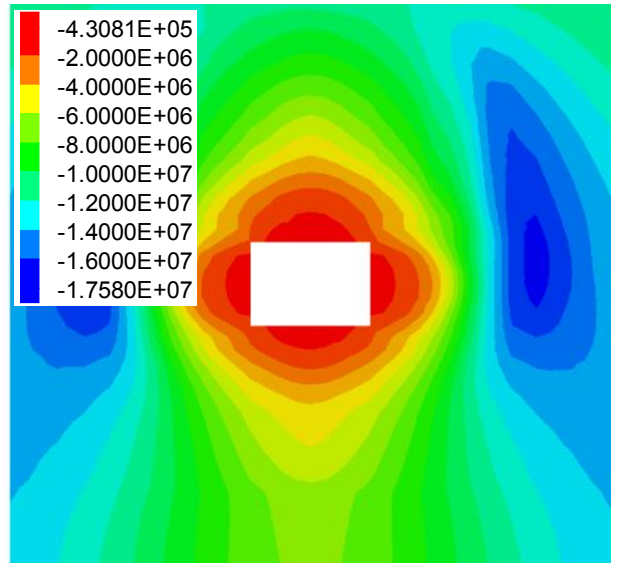

Fig. 5. Nephogram of maximum principal stress.

The distribution of roadway plastic area is shown in Figure 6. Shear-n unit in Figure 6 is the surrounding rock that is undergoing shear failure. It can be seen that there are obvious plastic failure areas in the two sidewalls. The sidewalls is soft and broken coal, so it is not suitable to support separately. Each supporting component should be connected to support as a whole.

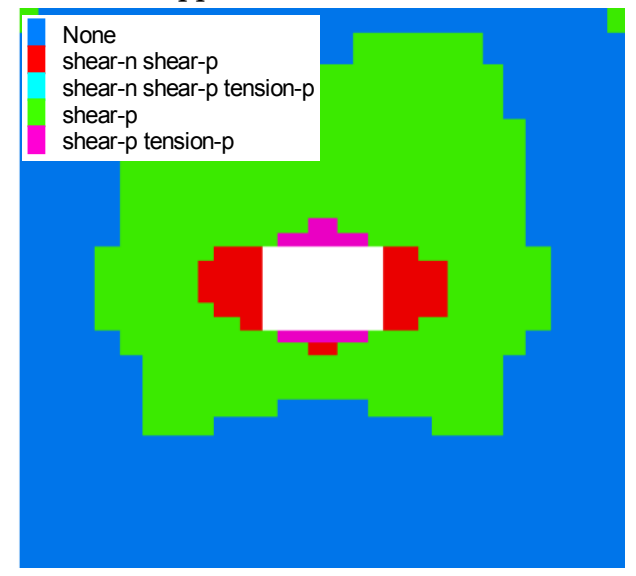

Fig. 6. Plasticity failure zone of roadway.

\section{Support effect of the original scheme}

Establish a variety of optimization schemes, use FLAC3D to carry out numerical simulation respectively, through the comparison of calculation results, optimize the original scheme, while ensuring the safety of the roadway and accelerating the excavation speed, combined with the comprehensive consideration of cost, get the optimal support scheme of the roadway.

\subsection{Put forward optimization scheme}

(1) Basis of proposed scheme

According to the coal industry standard, combined with the actual investigation of the roadway, through the numerical simulation, the supporting state of the original scheme is analyzed in detail, and its shortcomings are studied. At the same time, considering the factors of roadway stability, economy, excavation speed, etc., the optimization scheme of the roadway is proposed.

(2) Optimization schemes

Scheme 1: The anchoring method of the side bolt is resin lengthening anchoring, each of which is supported by Z2355 and K2355 type anchoring agent, and other supporting parameters are the same as the original scheme.

Scheme 2: $\Phi 20 \times 2200 \mathrm{~mm}$ is adopted for the side bolt, and other supporting parameters are the same as scheme 1.

Scheme 3: BHW-3-280-2500-3 W-type steel band is used to connect the side bolt into a whole. Other supporting parameters are the same as scheme 2 .

Scheme 4: The top row of side bolts inclines $15^{\circ}$ upward, and other supporting parameters are the same as scheme 3.

Scheme 5: The roof bolt is $\Phi 20 \times 2200 \mathrm{~mm}$, and the anchor cable is used instead of the roof bolt in the middle position. Other supporting parameters are the same as scheme 4 .

\subsection{Numerical simulation results and analysis}

The numerical simulation results are shown in Table 2.

Table 2. Coal roadway deformation value and ratio.

\begin{tabular}{|c|c|c|c|c|}
\hline Scheme & Roof & $\begin{array}{c}\text { Left } \\
\text { sidewall }\end{array}$ & $\begin{array}{c}\text { Right } \\
\text { sidewall }\end{array}$ & Floor \\
\hline Original & 33.14 & 56.26 & 55.71 & 11.69 \\
\hline $\begin{array}{c}\text { Scheme } \\
1\end{array}$ & 32.13 & 54.65 & 54.78 & 11.52 \\
\hline $\begin{array}{c}\text { Scheme } \\
2\end{array}$ & 31.83 & 53.64 & 53.48 & 11.46 \\
\hline $\begin{array}{c}\text { Scheme } \\
3\end{array}$ & 29.47 & 43.60 & 43.51 & 11.50 \\
\hline $\begin{array}{c}\text { Scheme } \\
4\end{array}$ & 28.75 & 42.51 & 42.28 & 11.44 \\
\hline $\begin{array}{c}\text { Scheme } \\
5\end{array}$ & 28.88 & 42.57 & 42.34 & 11.45 \\
\hline
\end{tabular}

Compared with the original scheme, scheme 1 adopts two anchorage agents to increase the anchorage length and the anchorage force of the side bolt. The simulation results show that not only the sidewall of roadway is effectively controlled, but also the deformation of the roof is reduced by $3.05 \%$, achieving a better supporting effect. Considering the large failure depth of the side sidewall, scheme 2 increases the length of the side bolt, so that the surrounding rock bolt is anchored on the more stable surrounding rock, the deformation of the roadway is reduced, the deformation of the left sidewall is reduced by $4.66 \%$, and the roof is reduced by $3.95 \%$. 
Considering the surrounding rock fragmentation of the roadway, scheme 3 connects the side bolt into a whole through W-type steel band, which is beneficial to connect the bolt's anchoring force into a whole and improve the stress state of the sidewall. The results show that the deformation of the sidewall is greatly reduced by $22.50 \%$, and the deformation of the roof is reduced by $11.07 \%$. It can be seen that the strong roof can be realized through the strong sidewall, which enhances the overall stability of the roadway. Considering the stress concentration in the corner of the roadway, the top row of bolts in scheme 4 inclines $15^{\circ}$ upward, strengthening the corner support of the roadway, improving the stress state of the surrounding rock, and further reducing the deformation of the surrounding rock. In scheme 5, the length of the roof bolt is changed to the same type of the side bolt, which is conducive to the unity of the construction, the improvement of the support speed, the replacement of the middle bolt by the anchor cable, and the connection of the roof bolt and the anchor cable into a whole through the W-type steel band, so as to play the coupling role, connect the anchor force of the bolt and the anchor cable into a whole, and reduce the support cost. The simulation results show that compared with the original scheme, the sidewall deformation is reduced by $24.33 \%$, roof deformation is reduced by $12.85 \%$, floor deformation is reduced by $2.05 \%$, and the overall stability is guaranteed. Considering the stability, cost and support speed of roadway, scheme 5 is better.

\subsection{Optimal support scheme}

According to the above study, scheme 5 is the optimal support scheme. The optimal support form is shown in Figure 7 and figure 8.

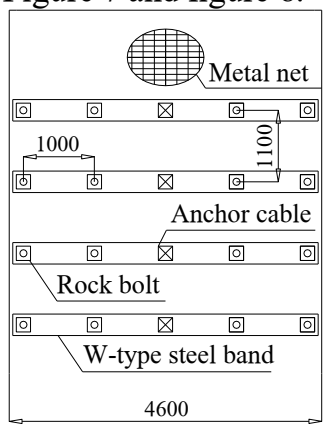

Fig. 7. Roof support.

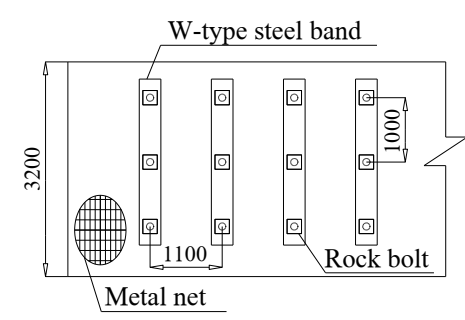

Fig. 8. Sidewall support.
Roof support: adopt bolt + anchor cable + W-type steel band + net support. The roof bolt adopts $\Phi 20 \mathrm{x}$ $2200 \mathrm{~mm}$ threaded steel bolt. The bolt and anchor cable are arranged in the same row, the specification of roof anchor cable is $\Phi 17.8 \times 6400 \mathrm{~mm}$, and the spacing between anchor cables is $1100 \mathrm{~mm}$. BHW-3-280-4200-5 steel band is adopted for the roof, and metal net is laid.

Sidewall support: adopt bolt $+\mathrm{W}$-type steel band + net support. The side bolt adopts $\Phi 20$ x $2200 \mathrm{~mm}$ steel bolt, each of which uses Z2355 and K2355 type anchoring agent. The top side bolt is $500 \mathrm{~mm}$ away from the roof, and the top side bolt inclines upward by $15^{\circ}$. BHW-3-280-2500-3 W-type steel band is used for the sidewall, and metal net is laid.

\section{Conclusion}

(1) The support of soft and broken coal roadway should pay attention to the support of the sidewall. By increasing the anchorage length and depth of the side bolt, combined with the W-type steel band of the side, the anchorage force and the overall stress of the bolt can be improved, so as to achieve the effect of improving the support strength of the sidewall, and further realize the strong roof by strengthening the sidewall to maintain the stability of the roadway.

(2) The support of soft and broken coal roadway should pay attention to the support of the corner. The support of the corner can be strengthened by tilting the rock bolt 15 degrees, so as to relieve the stress concentration of the corner, make the stress state of the surrounding rock of the roadway more reasonable, and improve the safety of the roadway.

(3) The number and space position of roof bolt and anchor cable in soft and broken coal roadway should be reasonably arranged. W-type steel band should be used to connect the bolt and anchor cable together to play the role of coupling support, so as to achieve the overall support effect, improve the roof stress state, form a reasonable stress circle around the roadway, and save the support cost.

\section{Acknowledgement}

The study was supported by the research project on support parameter optimization of surrounding rock in mining roadway of upper coal formation in Shuangliu coal mine, Yueqi Scholar Special Funding Project (No. 2018), and Fundamental Research Funds for the Central Universities (No. 2015QL02).

\section{References}

1. W.P. Huang, Q. Yuan, Y.L. Tan, J. Wang, G.L. Liu, G.L. Qu, C. Li, Tunn. Under. Sp. Tech. 73, 26 (2018)

2. X.S. Kong, R.L. Shan, T.D. Ju, J. Min. Saf. Eng. 34, 464 (2017)

3. H.P. Kang, M.J. Fan, F.Q. Gao, H. Zhang, Chin. J. Roc. Mech. Eng. 34, 2227 (2015)

4. R.L. Shan, X.S. Kong, F.Y. Yan, C. Meng, Chin. J. Roc. Mech. Eng. 34, 2336 (2015)

5. M.C. He, Q. Lu, Z.G. Tao, J. Chin. Univ. Min. Tech. 47, 213 (2018)

6. H.P. Kang, Chin. J. Roc. Mech. Eng. 29, 649 (2010)

7. Z.G. Tao, Z. Zhu, W.S. Han, Adva. Mech. Eng. 10, 244 (2018)

8. R.L. Shan, X.S. Kong, Z.T. Wei, M.Z. Li, S.J. Yang, L. Tian, Chin. J. Roc. Mech. Eng. 32, 1304 (2013)

9. H.H. Yuan, R.L. Shan, X.G. Su, Arab. J. Geosci. 11,767 (2018) 